\title{
RENAL DISEASE AND DRUG THERAPY IN RHEUMATOID ARTHRITIS
}

\author{
BY \\ A. A. H. LAWSON AND N. MACLEAN \\ From the Rheumatic Unit, the Northern General Hospital, Edinburgh, \\ and the Pathology Department, the Western General Hospital, Edinburgh
}

The terminal phases of rheumatoid arthritis may be complicated by severe renal disease. For example, Kuhns and Joplin (1936) found that eleven of 76 (14.4 per cent.) patients with atrophic arthritis died of nephritis, and recently Duthie, Brown, Truelove, Baragar, and Lawrie (1964) reported a similar incidence $(17 \cdot 3$ per cent.) in 74 patients who died after suffering from rheumatoid arthritis for 10 or more years.

A number of lesions may be concerned in the renal failure. Gedda (1955) held amyloidosis to be responsible for uraemia in nine of 45 of his patients who died, and chronic diffuse glomerulonephritis was present in another two of the fatal cases. Vascular lesions similar to or identical with polyarteritis affecting the kidney alone or with other organs have been described in rheumatoid arthritis (Dawson, 1940; Bennett, 1943; Ball, 1954; Schmid, Cooper, Ziff, and McEwan, 1961).

A high incidence not only of pyelonephritis but also of renal papillary necrosis (RPN) was found by Clausen and Pedersen (1961) in a study of the pathological records of eighty patients dying with rheumatoid arthritis in Copenhagen, and was attributed to the use of analgesic mixtures containing phenacetin. In our own necropsies on patients with rheumatoid arthritis, we noticed an unusual frequency of the chronic or sclerotic form of RPN (Schourup, 1957) which is said to be characteristic of phenacetin nephropathy (Sanerkin and Weaver, 1964) and because of this, other records were reviewed in an attempt to assess the influence of drug therapy upon renal disease in rheumatoid arthritis.

\section{The Investigation}

A review was made of the records of a group of 61 (17 men and 44 women) patients who had attended the Rheumatic Unit, Northern General Hospital, Edinburgh. All of them had suffered from classical or definite rheumatoid arthritis (American Rheumatism Association criteria, 1959). 33 who had died in the years 1957-65 had been examined post mortem by one of us (N.M.); the necropsy records of another 28 dying during the same period were also available and were studied together with the histological specimens of the kidneys of 58 of these patients.

A similar pathological study was made of 120 patients matched for age and sex, who had died of diseases other than rheumatoid arthritis: one female with rheumatoid arthritis in the 10 to 19-year age group whose illness was complicated by disseminated lupus erythematosus was unmatched. All the post-mortem examinations of the control group had been performed by one pathologist (N.M.) during the years 1959-1962, but were otherwise unselected.

The case records of the 61 patients with rheumatoid arthritis were analysed with particular reference to drug therapy, coincidental disease, mode of death, and duration of polyarthritis. None of these patients suffered from diabetes mellitus or from urinary obstruction.

\section{Results}

Of the 61 cases of rheumatoid arthritis, $44(72 \cdot 1$ pet cent.) (11 men and 33 women) showed significant renal disease at necropsy (Table $I$, overleaf), and 21 (34.4 per cent.) ( 3 men and 18 women) died primarily of renal disease. Renal papillary necrosis (RPN) occurred in twelve women ( $27 \cdot 3$ per cent.) and in one man ( 5.9 per cent.), and chronic pyelonephritis was also more frequent in women. By contrast, severe arterial disease in the kidney occurred more often in men. Renal disease was common in all age groups after the age of 40 years and did not appear to increase with age, but there appeared to be some association between duration of disease and the presence of RPN (Table II, overleaf).

Renal papillary necrosis.-Major forms of RPN associated with acute pyelonephritis and involving most of the papillae are readily recognized, but when the disease is old and involves only a few of the papillae its presence may be overlooked at necropsy. On the other hand, focal areas of RPN or scars due to sloughed papillae which escape recognition by the naked eye may become obvious on microscopic examination. In the present series, only the thirteen cases in which the diagnosis was made by the naked eye have been counted as cases of RPN, and for this 
TABLE I

INCIDENCE OF RENAL DISEASE IN 61 MEN AND WOMEN DYING WITH RHEUMATOID ARTHRITIS

\begin{tabular}{|c|c|c|c|c|c|c|c|c|c|c|c|}
\hline \multirow{2}{*}{\multicolumn{7}{|c|}{$\begin{array}{l}\text { Pathological Assessment of } \\
\text { State of Kidneys }\end{array}$}} & \multicolumn{2}{|c|}{ Males } & \multicolumn{3}{|c|}{ Females } \\
\hline & & & & & & & \multirow{2}{*}{$\begin{array}{c}\text { Number } \\
\left.\begin{array}{l}0 \\
0 \\
1\end{array}\right\} 1\end{array}$} & \multirow{2}{*}{$\begin{array}{l}\text { Percentage } \\
\left.\begin{array}{r}0 \\
0 \\
5.9\end{array}\right\} 5 \cdot 9\end{array}$} & \multirow{2}{*}{$\begin{array}{c}\text { Number } \\
\left.\begin{array}{l}3 \\
3\end{array}\right\} 12\end{array}$} & \multicolumn{2}{|c|}{ Percentage } \\
\hline A. & $\begin{array}{c}\text { Renal Papillary Necrosis (RPN } \\
\text { with Acute Pyelonephritis (A } \\
\text { with Renal Amyloidosis (1 } \\
\text { with Chronic Pyelonephritis } \\
\text { Nephritis (CIN) .. }\end{array}$ & $\begin{array}{l}\text { N) } \\
\text { (AP) } \\
\text { with } \mathrm{A} \\
\text { is or } \mathrm{Ch} \\
.\end{array}$ & $\begin{array}{l}\ddot{P}) \\
\text { hronic In } \\
.\end{array}$ & $\begin{array}{l}\because \\
\text { nterstiti } \\
\cdots\end{array}$ & $\begin{array}{l}\cdots \\
\text { ial } \\
\cdots\end{array}$ & $\begin{array}{l}\cdots \\
\cdots\end{array}$ & & & & $\left.\begin{array}{r}6 \cdot 8 \\
6 \cdot 8 \\
13 \cdot 6\end{array}\right\}$ & \\
\hline B. & Renal Amyloidosis without RP & PN & . . & .. & .. & .. & 2 & $11 \cdot 8$ & 5 & $11 \cdot 4$ & \\
\hline C. & Acute Pyelonephritis without $\mathrm{R}$ & RPNo & or Amylo & loidosis & & .. & 1 & $5 \cdot 9$ & 2 & $4 \cdot 5$ & \\
\hline D. & $\begin{array}{c}\text { Chronic Pyelonephritis or } \\
\text { Amyloidosis } . .\end{array}$ & $\begin{array}{l}\text { CIN v } \\
\cdots\end{array}$ & $\begin{array}{l}\text { without } \\
.\end{array}$ & RPN, & AP, & $\begin{array}{l}\text { or } \\
.\end{array}$ & 3 & $17 \cdot 6$ & 10 & $22 \cdot 7$ & \\
\hline E. & Renal Arterial Disease .. & .. & . $\quad$. & . $\quad$. & . & . & 4 & $23 \cdot 6$ & 3 & $6 \cdot 8$ & \\
\hline F. & Congenital Anomaly .. & .. & $\cdots$ & . & $\cdots$ & $\cdots$ & 0 & $0 \cdot 0$ & 1 & $2 \cdot 3$ & \\
\hline & Total Renal Disease & $\cdots$ &. &. & .. & . & 11 & $64 \cdot 8$ & 33 & $74 \cdot 9$ & \\
\hline G. & No Significant Disease .. & $\cdots$ &.. & $\cdots$ & $\cdots$ & .. & 6 & $35 \cdot 2$ & 11 & $25 \cdot 1$ & \\
\hline & Total No. of Patients ... & .. & .. & .. & . & .. & 17 & & 44 & & \\
\hline
\end{tabular}

reason the apparent incidence $(21 \cdot 3$ per cent.) is almost certainly an underestimate. Thus in five other women there were, on microscopic examination, signs of old focal RPN, or of sloughing and scarring of the papillae.

In five cases of macroscopic RPN the necrosis was recent, and in four of them it was associated with acute pyelonephritis. The number of papillae involved in these acute cases varied from one in a single kidney to most papillae in both kidneys.

The necrosis in the remaining eight cases appeared to be old. In each of three of the eight cases only two papillae appeared to be involved, but in the other five the majority of papillae in both kidneys were affected.
Sloughing of the necrotic papillae had occurred in only one of the eight cases. In the remainder the necrotic papillae were commonly firm, yellow-grey, $\overrightarrow{c P}$ and often shrunken and brown-black at the tips. Sometimes necrosis appeared to have taken place $\mathrm{a}_{\mathbb{\Phi}}$ long time before death; focal calcification was com-3 mon, and in one case sufficient time had elapsed for@ ossification to occur (Fig. 1, opposite).

Chronic interstitial nephritis and chronic pyekenephritis.-Spühler and Zollinger (1953) describedbà distinctive histological appearance which they desîg-o nated chronic interstitial nephritis, and they noted that in some cases it was associated with the use of analgesics. The specificity of this histological

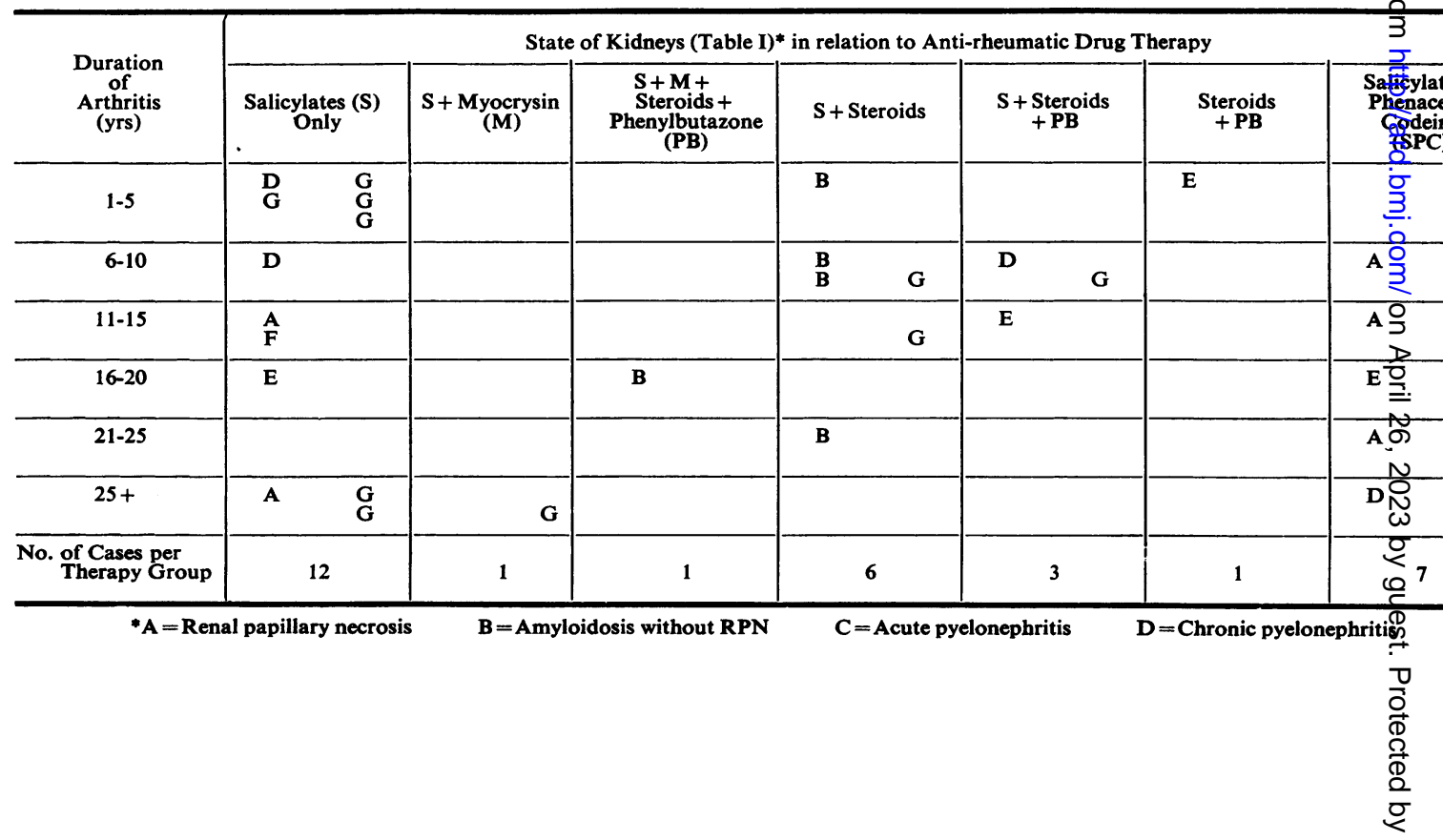




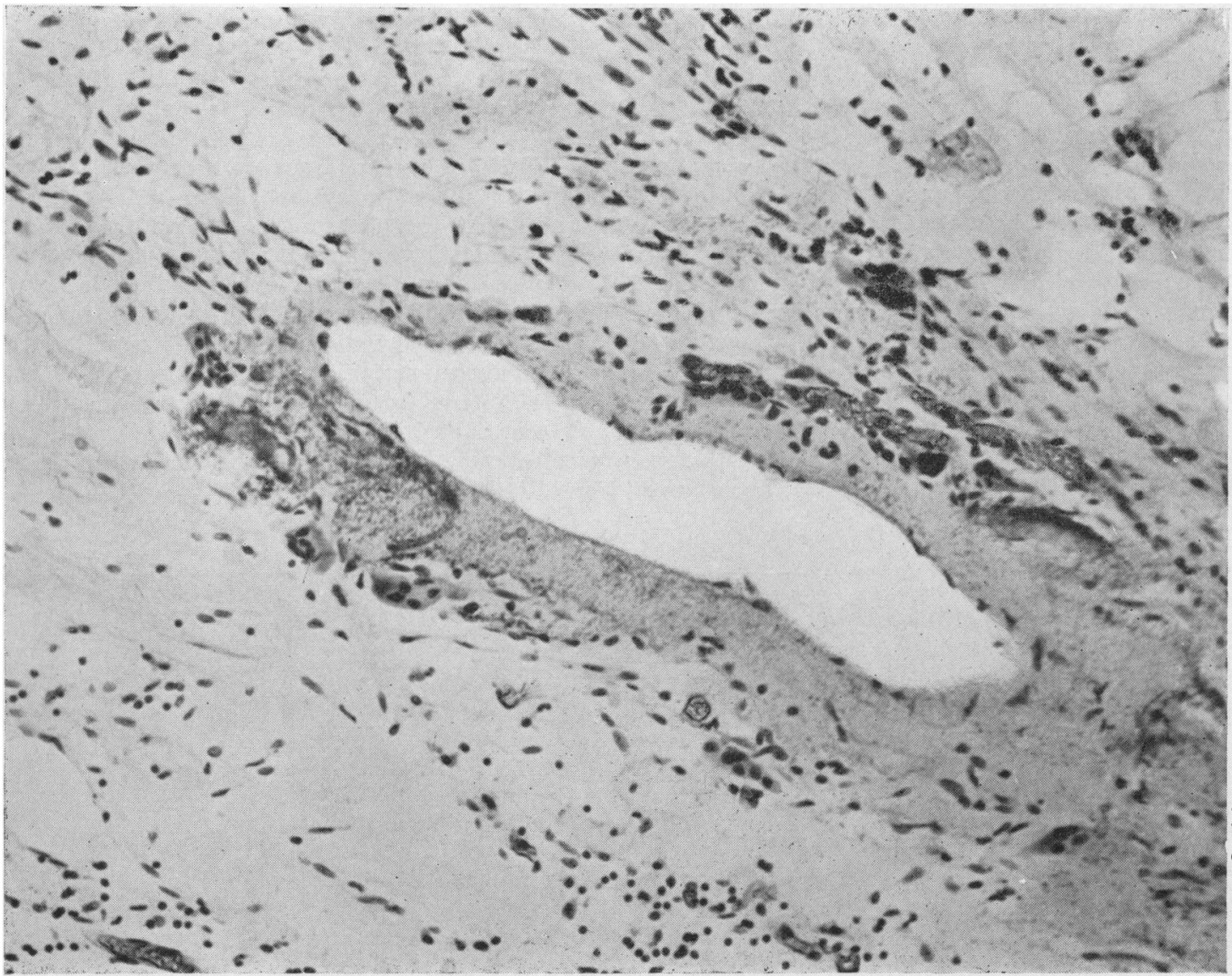

Fig. 1.-Spicule of bone with marrow cavity in necrotic renal papilla. Osteoclasts are present at the periphery.

$\times 125$.

G THERAPY RELATED TO DURATION OF ARTHRITIS AND STATE OF KIDNEYS

\begin{tabular}{|c|c|c|c|c|c|c|c|}
\hline \multicolumn{7}{|c|}{ State of Kidneys (Table I)* in relation to Anti-rheumatic Drug Therapy } & \multirow{2}{*}{$\begin{array}{l}\text { No. of } \\
\text { Cases } \\
\text { per Age } \\
\text { Group }\end{array}$} \\
\hline $\mathbf{S P C}+\mathbf{M}$ & $\mathbf{S P C}+\mathbf{M}+\mathbf{P B}$ & $\mathbf{S P C}+\mathbf{P B}$ & $\begin{array}{c}\mathbf{S P C}+\mathbf{M} \\
+ \text { Steroids }\end{array}$ & $\underset{\substack{\text { Steroids } \\
+ \text { PB }}}{\text { SPC }+ \text { M }}$ & $\begin{array}{l}\text { SPC+ } \\
\text { Steroids }\end{array}$ & $\begin{array}{c}\text { SPC+ } \\
\text { Steroids } \\
+ \text { PB }\end{array}$ & \\
\hline & & & G & & $\begin{array}{l}\text { D } \\
\text { D }\end{array}$ & & 10 \\
\hline ; & & G & $\begin{array}{l}\mathbf{B} \\
\mathbf{D}\end{array}$ & & C & & 13 \\
\hline $\mathbf{G}$ & & D & & & E & & 13 \\
\hline · & A & & & & $\stackrel{B}{C}$ & & 7 \\
\hline$:$ & & & $\mathbf{A}$ & D & & $\mathbf{A}$ & 8 \\
\hline . & & D & . & $\mathbf{E}$ & $\stackrel{\mathbf{A}}{\mathbf{D}}$ & & 10 \\
\hline 8 & 1 & 3 & 4 & 4 & 9 & 1 & 61 \\
\hline
\end{tabular}


picture has been questioned by Randerath (1958) and also by Sanerkin and Weaver (1964), who rightly point out that it has many features in common with chronic non-obstructive pyelonephritis. On the other hand, the presence of large areas of renal cortical atrophy showing disappearance of normal convoluted tubules, crowding together of well preserved glomeruli, and an absence of severe vascular degeneration (Fig. 2) is more common in nephropathy associated with analgesics than in other renal disease. Note was therefore made of this appearance during microscopic examination without implying that its pathogenesis differed from that of the chronic pyelonephritis found in other patients. "Chronic interstitial nephritis" was found in five of the thirteen cases of RPN, and in four of the remaining 48 cases. It is of interest that one of these four cases showed focal RPN on microscopic examination, and another? showed papillary erosion and scarring. The four? cases have been included in Group D (Table I) together with cases of chronic pyelonephritis.

The incidence of chronic pyelonephritis given in: Table I understates its frequency, because some of thes? patients with acute pyelonephritis or amyloidosiso also showed signs of chronic pyelonephritis, but wereo classified under the disease which was of most im portance at the time of death. A reasonable estimate of the frequency of non-obstructive pyelonephrition can, however, be obtained by aggregating RPN, and? acute and chronic pyelonephritis (Groups $\mathrm{A}, \mathrm{C}$, and $\mathrm{P}$ D, Table I). Thus five of the seventeen men $(29 \cdot 4 \overrightarrow{4}$ per cent.) and 24 of the 44 women ( 54.4 per cent. 5 were affected, giving a total incidence of 47.5 peet cent. in the 61 patients.

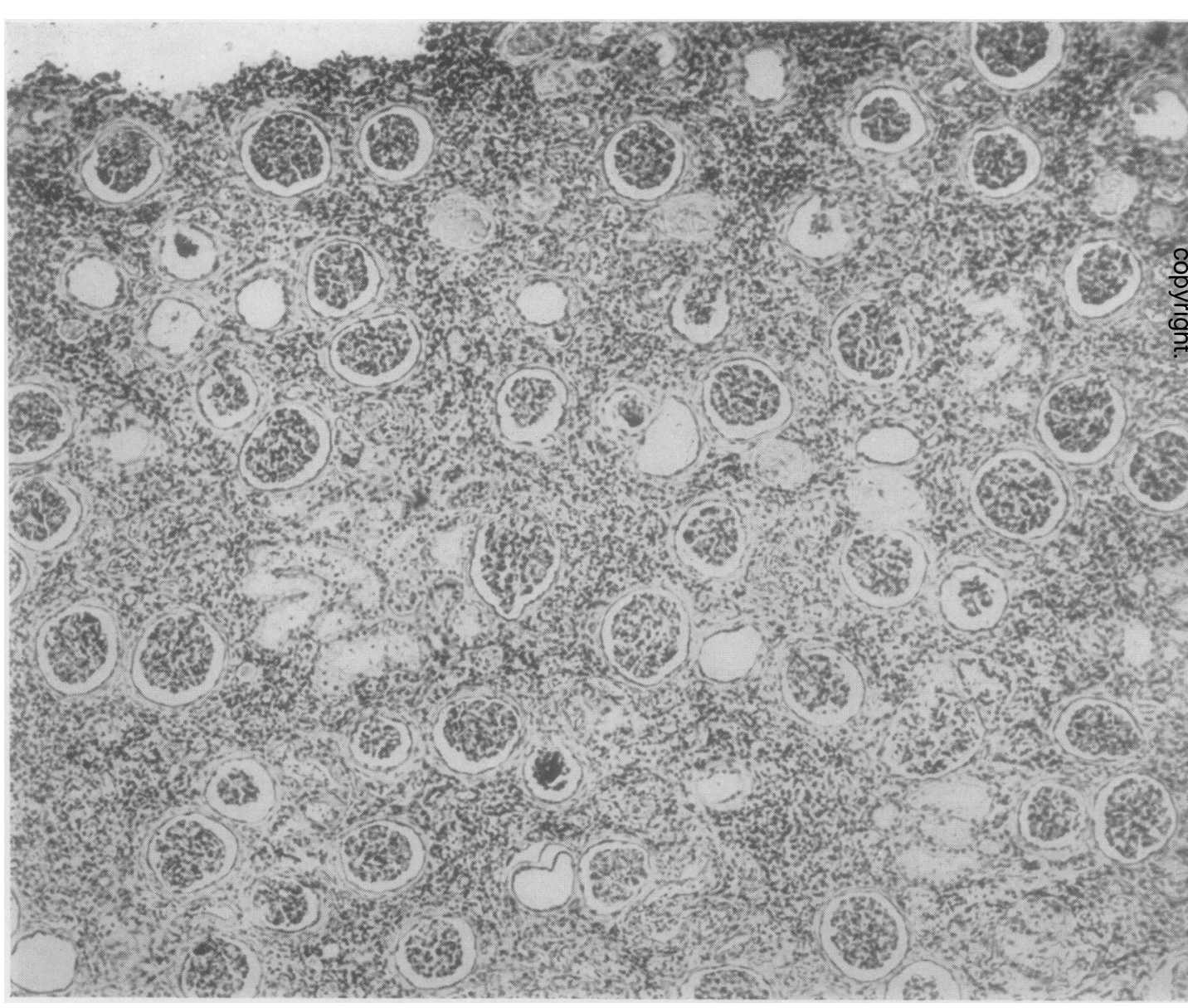

Fig. 2.-Renal cortex, showing atrophy of convoluted tubule and aggregation of relatively normal glomeruli.

$\times 50$. 
Renal amyloidosis.-Amyloidosis affected the kidneys in two of the seventeen men ( $11 \cdot 8$ per cent.) and in eight of the 44 women (18.2 per cent.), an overall incidence of 16.4 per cent. It occurred more frequently in the twelve women with RPN (25 per cent.) than in the remaining 32 women $(15.6$ per cent.).

Renal arterial disease.-The renal arteries and arterioles were frequently involved in the disease processes affecting the kidneys, and these cases are not considered separately. Occasionally, however, vascular abnormalities were the main cause of renal disease. Four of the seventeen men showed necrosis of renal arteries, arterioles, or glomeruli, and in two of them these lesions were associated with frank polyarteritis nodosa in other organs. Three of the 44 women showed renal vascular disease: in one the kidney was involved in a polyarteritic process which affected other organs; another showed arteriosclerotic nephrosclerosis; in the third, malignant hypertension was responsible.

Congenital abnormalities.-In one woman the left kidney was represented by a rudimentary cyst $2 \mathrm{~cm}$. in diameter. The other kidney showed compensatory hypertrophy with superadded arteriosclerosis.

Other renal disease. - Two of the men showed some glomerular endothelial proliferation similar to that described by Bell (1936). This condition was noted to occur in 63 per cent. of the cases of rheumatoid arthritis examined by Baggenstoss and Rosenberg (1943) and in 13 per cent. of the cases of Fingerman and Andrus (1943). The abnormality in our two cases was not associated with other renal disease, and because the clinical and pathological examinations did not suggest that serious renal disturbance had resulted, the cases have been classified with those showing no significant renal disease.

Two of the patients showed more than one type of renal disease. One woman who died from septicaemia and acute pyelonephritis in the left kidney had formerly been under treatment for nephritis, and at death showed glomerular changes suggestive of chronic membranous glomerulonephritis in the right kidney. Another woman who developed disseminated lupus erythematosus and renal amyloidosis also showed the renal vascular effects of disseminated lupus erythematosus.

\section{Comparison of the Incidence of Renal Disease in Rheumatoid Patients and in Patients dying of Other Disease}

The last-mentioned patient, a girl aged 19, was unmatched in the control series because of age and has been omitted from this comparison. Renal disease was commoner in the remaining sixty patients with arthritis than in controls matched for age and sex. Thus $\mathbf{4 3}$ of the sixty patients with rheumatoid arthritis $(71 \cdot 7$ per cent.) suffered from significant renal disease, whereas only thirty of the 120 control series ( 25 per cent.) showed significant renal disease at death. They included six cases of tumour causing obstruction of the genito-urinary tract, seven of diabetic renal disease, two with hydronephrosis, and one with renal lithiasis. Renal vascular disease including embolic infarcts accounted for six cases, membranous glomerulonephritis for one, and unilateral renal agenesis for another.

Pyelonephritis unassociated with diabetes mellitus or urinary obstruction occurred in only seven patients of the control group ( 5.8 per cent.), being chronic in six and acute in one. Three of the seven patients with diabetic renal disease also showed pyelonephritis, giving a total incidence of non-obstructive pyelonephritis of $8 \cdot 3$ per cent. amongst the 120 controls, or of 9 per cent. amongst the 111 controls without urinary obstruction. Non-obstructive pyelonephritis occurred in 29 of the sixty patients with rheumatoid arthritis, an incidence which was significantly higher than in the control group $(\mathrm{P}<0 \cdot 001)$.

\section{Drug Therapy and its Influence on Renal Disease}

Fourteen different combinations of drugs were use at one time or another in the treatment of the 6t patients, and in Table II they are related to renal disease and to the duration of arthritis. The dosages and periods of administration of the various drugs were not uniform, but it can be accepted that the drugs mentioned were administered in at least therapeutic doses for a significant period of time.

Salicylates.-All but one of the patients received salicylates, usually in the form of soluble aspirin ("Solprin"), and in general the total dose of salicylates related roughly to the duration of arthritis. In 23 of the patients receiving salicylates there was no record of phenacetin administration. Five of these 23 patients ( 22 per cent.) developed non-destructive pyelonephritis, a higher proportion than in the control group, where ten cases ( 9 per cent.) were present in a total of the 111 patients who were free from urinary obstruction of one sort or another. The difference, however, did not attain statistical signifi- cance until the seven control cases with diabetic renal disease were omitted from consideration. None of the patients with rheumatoid arthritis suffered from diabetes mellitus.

Phenacetin.-The total dosage of phenacetincodeine compounds was also related to the duration 
of disease when they were administered from an early stage of the arthritis. This, however, was less constant than in the case of salicylates, and it is clear that the number of patients recorded as receiving phenacetin tended to increase with the duration of the disease (Table II). Thus up to 10 years, ten of 23 patients received it in comparison with 27 of 38 cases of longer duration.

Consumption of phenacetin compounds was excessive in a few cases, and there were records of this in one man and five women. All of these six patients had serious renal disease at death: four showed RPN and two of the four also had renal amyloidosis; one showed interstitial nephritis and amyloidosis; the remaining patient had chronic pyelonephritis in one kidney and pyonephrosis in the other.

The increased frequency of severe renal disease in patients receiving phenacetin was not confined to those taking it to excess. When all patients receiving phenacetin were considered, the incidence of RPN was still substantially greater than in those patients receiving no phenacetin (Table III). The difference in the incidence of non-obstructive pyelonephritis between the two groups was greater (Table IV), and was significant even in the 31 patients taking phenacetin in doses not known to be excessive $(P<0.001)$.

Steroids.-29 patients received steroids, mainly prednisolone, in therapeutic doses, eighteen with phenacetin and eleven without. Only three of the $29 \stackrel{\overparen{D}}{\widetilde{D}}$ patients who received sterids $\left(10.3\right.$ per cent.) $\frac{\varsigma}{\zeta}$ developed RPN in comparison with ten of the 32 cases (31.2 per cent.) who received no steroids $(P<0.05)$. There was, however, little difference $\vec{F}$ between the groups in the incidence of non-obstruc- $?$ tive pyelonephritis, which was present in twelve of the 29 patients $\left(41.4\right.$ per cent.) receiving steroids, as $\frac{\overline{\bar{\omega}}}{\overline{0}}$ against seventeen of 32 patients $\left(50.3\right.$ per cent.) not $\frac{\Phi}{\Phi}$ receiving steroids.

Eight of the ten patients who developed renal के amyloidosis had been treated by steroids. Thus, $\vec{\circ}$ eight of 29 patients receiving steroids developed amyloidosis in contrast with only two of the $32 \vec{\omega}$ patients not receiving steroids $(\mathrm{P}<0.05)$.

Myocrysin and Phenylbutazone.-Nineteen patients $\tilde{i}$ received myocrysin with other drugs, and fourteen of received phenylbutazone with other drugs. No influence of these two drugs upon the incidence of $\underset{\nexists}{\nexists}$ significant renal disease was obviously evident.

\section{Discussion}

The outstanding finding in this study was the high proportion $\left(72 \cdot 1\right.$ per cent.) of patients with rheuma- $\frac{D}{3}$ toid arthritis who also had renal disease. In common with most workers, we found that amyloidosis frequently occurred in long-standing cases af rheumatoid arthritis. Pollak, Pirani, Steck, an Kark (1962) noted that amyloidosis was found

TABle III

INCIDENCE OF RENAL PAPILLARY NECROSIS (RPN) RELATED TO PHENACETIN INTAKE

\begin{tabular}{|c|c|c|c|c|c|c|}
\hline \multirow{3}{*}{$\begin{array}{c}\text { Duration } \\
\text { of } \\
\text { Arthritis } \\
\text { (yrs) }\end{array}$} & \multicolumn{3}{|c|}{ No Phenacetin } & \multicolumn{3}{|c|}{ Phenacetin } \\
\hline & \multirow{2}{*}{$\begin{array}{l}\text { No. of } \\
\text { Patients }\end{array}$} & \multicolumn{2}{|c|}{ With RPN } & \multirow{2}{*}{$\begin{array}{l}\text { No. of } \\
\text { Patients }\end{array}$} & \multicolumn{2}{|c|}{ With RPN } \\
\hline & & No. & Percentage & & No. & Percentage \\
\hline $\begin{array}{c}1-10 \\
11-20 \\
\text { Over } 20\end{array}$ & $\begin{array}{r}13 \\
6 \\
5\end{array}$ & $\begin{array}{l}0 \\
1 \\
1\end{array}$ & $\begin{array}{r}0.0 \\
16 \cdot 7 \\
20.0\end{array}$ & $\begin{array}{l}10 \\
14 \\
13\end{array}$ & $\begin{array}{l}2 \\
4 \\
5\end{array}$ & $\begin{array}{l}20 \cdot 0 \\
28 \cdot 6 \\
38 \cdot 5\end{array}$ \\
\hline Total & 24 & 2 & & 37 & 11 & \\
\hline
\end{tabular}

$x^{2}=3 \cdot 96 ; \mathrm{P}<0.05$

TABLE IV

INCIDENCE OF NON-OBSTRUCTIVE PYELONEPHRITIS (NOP) RELATED TO PHENACETIN INTAKE

\begin{tabular}{|c|c|c|c|c|c|c|}
\hline \multirow{3}{*}{$\begin{array}{l}\text { Duration } \\
\text { of } \\
\text { Arthritis } \\
\text { (yrs) }\end{array}$} & \multicolumn{3}{|c|}{ No Phenacetin } & \multicolumn{3}{|c|}{ Phenacetin } \\
\hline & \multirow{2}{*}{$\begin{array}{l}\text { No. of } \\
\text { Patients }\end{array}$} & \multicolumn{2}{|c|}{ With NOP } & \multirow{2}{*}{$\begin{array}{l}\text { No. of } \\
\text { Patients }\end{array}$} & \multicolumn{2}{|c|}{ With NOP } \\
\hline & & No. & Percentage & & No. & Percentage \\
\hline $\begin{array}{c}1-10 \\
11-20 \\
\text { Over } 20\end{array}$ & $\begin{array}{r}13 \\
6 \\
5\end{array}$ & $\begin{array}{l}3 \\
1 \\
1\end{array}$ & $\begin{array}{l}23 \cdot 1 \\
16 \cdot 7 \\
20 \cdot 0\end{array}$ & $\begin{array}{l}10 \\
14 \\
13\end{array}$ & $\begin{array}{r}7 \\
6 \\
11\end{array}$ & $\begin{array}{l}70 \cdot 0 \\
42 \cdot 8 \\
84 \cdot 6\end{array}$ \\
\hline Total & 24 & 5 & & 37 & 24 & \\
\hline
\end{tabular}


18.7 per cent. of the published reports of 353 necropsies on rheumatoid patients, a figure close to that for renal amyloidosis in the present series $(16 \cdot 4$ per cent.). The significance of the glomerulitis of Bell (1936), noted frequently in rheumatoid arthritis by Baggenstoss and Rosenberg (1943), has been questioned in recent years. The investigations of Pollak and others (1962), Allander, Bucht, Lövgren and Wehle (1963), and Brun, Olsen, Raaschou, and Sørensen (1965) failed to demonstrate the lesion, and our own observations do not suggest that this is a specific feature of rheumatoid disease.

In the present series, renal arterial disease was found to be more common in men than in women. Disseminated polyarteritis accounted for three of the seven cases, and its incidence in our 61 patients ( 4.9 per cent.) may be compared with the aggregate of four other series (Levin, Rivo, Scott, Figueroa, Fred, and Barrett, 1953; West and Newns, 1953; Kemper, Baggenstoss, and Slocumb, 1957; Johnson, Smyth, Holt, Lubchenko, and Valentine, 1959). In a total of 271 necropsies, polyarteritis was reported in eleven cases ( 4 per cent.). The combined experience of 332 post-mortem examinations, therefore, does not suggest that polyarteritis accounts for a high proportion of the renal disorders of rheumatoid arthritis.

The incidence of renal disease in our patients is comparable with that found by Clausen and Pedersen (1961) in a similar group of patients in Copenhagen. In both groups much of the renal disease was due to various forms of non-obstructive pyelonephritis, and in both there was an unusual frequency of renal papillary necrosis. Brun and others (1965) also found a disproportionately high incidence of "chronic interstitial nephritis" in biopsy investigation of 32 cases. There is, therefore, some agreement in recent pathological studies that pyelonephritis and RPN are common in rheumatoid arthritis. Previously, these conditions were seldom mentioned and never stressed, although their major manifestations are readily recognizable pathologically. It is possible, therefore, that they may have increased in frequency, and, indeed, Clausen and Pedersen (1961) found that the incidence of uraemia amongst their rheumatoid patients increased from 20 per cent. in the years $1951-56$ to 46 per cent. in 1957-60, whilst RPN increased from 7.7 to 36.5 per cent. in the same period. They attributed this difference to an increasing use of analgesics containing phenacetin, and they noted a heavy intake of such drugs in all the patients with RPN.

There can be little doubt that analgesic mixtures containing phenacetin taken to excess over a period of years can cause permanent renal damage including papillary necrosis, but the role which phenacetin itself plays in causing renal disease is controversial. Those who believe in a true phenacetin nephropathy include Spühler and Zollinger (1953), Moeschlin (1957), Schourup (1957), Lindeneg, Fischer, Pedersen, and Nissen (1959), Larsen and Møller (1959), Buchanan (1961), Nordenfelt and Ringertz (1961), Jacobs and Morris (1962), Ross (1962), and Grimlund (1963), amongst others. On the other hand, there are those who suggest that the factors which may be involved are complex, since other drugs are almost invariably administered simultaneously with phenacetin (Schreiner, 1962; Gilman, 1964; Prescott, 1965). Moreover, as far as rheumatoid arthritis was concerned, Sørensen (1963) was unable to demonstrate any relationship between phenacetin or any other drug and renal function as determined by the creatinine clearance test. Other tests may, however, be more appropriate for conditions in which the tubules suffer more severely than the glomeruli. Uehlinger (1958), for example, found that interstitial nephritis particularly affected the concentrating power, and Bengtsson (1962) noted a disproportionate reduction in concentration as compared with glomerular infiltration in cases of RPN.

Assessment of drug therapy in relation to renal disease in a retrospective study presents obvious difficulties. Documentation of the drugs given is not always complete; there is always the possibility of self-administration of analgesics unknown to the medical staff; and, finally, the prolonged therapy often includes several medicaments each of which may contribute to the development of renal disease. For example, numerous reports have suggested that salicylates are nephrotoxic. Prescott (1965) has reviewed this subject and has demonstrated in human volunteers the nephrotoxic effect not only of aspirin but also of phenacetin and caffeine. Phenylbutazone has been reported to cause renal insufficiency (Kling, 1952; Wilson, 1953; Lipsett and Goldman, 1954; Zinn, 1954; Belart, 1955). Myocrysin therapy may be complicated by proteinuria or microscopic haematuria (Sundelin, 1941; Snorrason, 1950). The influence of corticosteroids in bringing about renal disease is difficult to assess, particularly with regard to amyloidosis, because patients treated with them are often those who have a severe form of disease for which more than one type of therapy is tried.

Some of these factors do not appear to have been involved in causation of the renal disease in the present cases. Caffeine was not incorporated into the analgesic mixtures known to have been used and codeine, which was incorporated, has no known nephrotoxic 
effect. Myocrysin and phenylbutazone appeared to have had no influence upon the incidence of renal disease.

By contrast, the administration of steroids was accompanied by an increased frequency of renal amyloidosis and by a decrease in the incidence of RPN. It has been suggested that corticosteroid therapy may cause exacerbation of amyloid disease and by implication accelerate or induce its onset (Paulsen, 1950; Teilum and Lindahl, 1954). Gardner (1962), however, was unable to find support for this suggestion in a histological review of 108 necropsies on rheumatoid subjects. Only one of his eight cases treated with hormones $(12.5$ per cent.) developed amyloidosis, whilst twelve of one hundred receiving other therapy (12 per cent.) also developed amyloidosis. Gardner's results and those of the present study may be compared, since both population groups were drawn from the same localities and were treated in the same units. The incidence of amyloidosis was higher in the present series ( 16.4 per cent.), but the difference is not significant, and the comparison does not suggest that the more liberal use of corticosteroid therapy caused a marked increase in amyloidosis. If corticosteroids had been responsible for a 4-fold increase in renal amyloidosis, as our data at first sight suggested, the total incidence in our series should have been substantially higher. The possibility that corticosteroids had an effect cannot be excluded but, on the other hand, it seems reasonable to suppose that much of the higher incidence of amyloidosis could be accounted for by selection of the more severe cases for hormonal therapy. This selection is known to have been made, and our findings probably reflect the pronounced tendency of the severe forms of rheumatoid arthritis to cause amyloidosis.

The lower incidence of RPN in patients who received corticosteroids was not associated with a corresponding reduction in the amount of nonobstructive pyelonephritis, and it is possible that the effect of corticosteroids in this respect may have been exerted during episodes of acute pyelonephritis. Bengtsson (1962) obtained a history of one or more attacks of acute pyelonephritis in 78 per cent. of his cases of chronic non-obstructive pyelonephritis, and in 68 per cent. of the cases of RPN. It seems reasonable to suggest that corticosteroids, by their action in diminishing the intensity of tissue reaction, may prevent some of the worst effects of acute pyelonephritis, including papillary necrosis.

The major part of the renal disease found post mortem in our cases of rheumatoid arthritis was due to various forms of non-obstructive pyelonephritis.
The frequency of RPN was particularly significant, since it is rarely encountered except in association with the acute pyelonephritis of diabetes mellitus or $\frac{}{\omega}$. urinary obstruction, unless analgesics have been consumed in substantial quantity. All except one of ours cases received salicylates or salicylates and phenace $\overrightarrow{0}$ tin, which have both been shown to be nephrotoxico (Prescott, 1965); 23 patients who received salicylates, alone or in combination with other drugs exceptiळ phenacetin, showed more non-obstructive pyelo nephritis than the control group, but the differences did not attain a level of significance. Although the $\vec{P}$ numbers were small, the findings at least suggested $-\overrightarrow{-}$ that neither rheumatoid arthritis itself nor the administration of salicylates (alone or in combinationg with the other drugs used in this series, excepting phenacetin) could be held solely responsible for ther high incidence of renal disease.

Administration of phenacetin in combination with salicylates, on the other hand, was associated with $a_{\circ}$ significant increase in the amount of non-obstructive pyelonephritis. Our data, therefore, suggested that mixtures of phenacetin and salicylates had a damag-क ing effect upon the kidneys of patients with rheumatoid arthritis which was not equalled by salicylates 3 given alone or in combination with the other drugs@ used in this series. The effect tended to increase wigh $\vec{C}$ the duration of the arthritis, but it caused seriogs renal disease within 10 years of the onset of the rheumatoid state even in patients not known to taking salicylate and phenacetin to excess. Mixtures containing salicylates and phenacetin are, therefore, potentially harmful. Prolonged use of this com- $\frac{\circ}{\mathbb{D}}$ bination of drugs incurs a risk of serious renal im- $\cong$ pairment which is probably still underestimated in $\overrightarrow{\vec{O}}$ the United Kingdom.

Summary
The incidence of renal disease in patients with? rheumatoid arthritis was studied in the clinical and pathological records in 61 cases $(17$ men and 44 ? women) and the renal histology was reviewed.

Significant renal disease was found in 72 per cent. of the patients, and renal papillary necrosis (RPN) in $\frac{\mathrm{F}}{3}$ 21 per cent.; 34 per cent. of the patients had died in renal failure.

Drug therapy appeared to have an influence on the $\frac{7}{0}$ amount of renal disease. The incidence of the various forms of non-obstructive pyelonephritis $N_{\odot}$ was significantly higher in patients receiving phenacetin. Renal amyloidosis was more common and ${ }_{N}$ renal papillary necrosis less common in the patients $\omega$ who received corticosteroids.

The significance of these findings is discussed.

Our thanks are due to Dr. J. J. R. Duthie for his helpful advice and for permission to report on his patients. We? 
are also grateful to numerous colleagues who allowed us to examine clinical and necropsy records and histological material, and particularly to Dr. A. J. Murray Drennan. During the period of investigation, the Rheumatic Unit, Northern General Hospital, Edinburgh, was in receipt of funds from the Medical Research Council, the Arthritis and Rheumatism Council, the Nuffield Foundation, and Boots Pure Drug Company.

\section{REFERENCES}

Allander, E., Bucht, H., Lövgren, O., and Wehle, B. (1963). Acta rheum. scand., 9, 116.

American Rheumatism Association (1959). Ann. rheum. Dis., 18, 49.

Baggenstoss, A. H., and Rosenberg, E. F. (1943). Arch. Path. 35, 503.

Ball, J. (1954). Ann. rheum. Dis., 13, 277.

Belart, W. (1955). Münch. med. Wschr., 97, 564.

Bell, E. T. (1936). Amer. J. Path., 12, 801.

Bengtsson, U. (1962). Acta med. scand., 172, Suppl. 388.

Bennett, G. A. (1943). Ann. intern. med., 19, 111.

Brun, C., Olsen, T. S., Raaschou, F., and Sørensen, A. W. (1965). Nephron, 2, 65.

Buchanan, J. G. (1961). N.Z. med. J., 60, 207.

Clausen, E., and Pedersen, J. (1961). Acta med. scand., $170,631$.

Dawson, M. H. (1940). See note in Hench and others (1940), p. 1941.

Duthie, J. J. R., Brown, P. E., Truelove, L. H., Baragar, F. D., and Lawrie, A. J. (1964). Ann. rheum. Dis., 23, 193.

Fingerman, D. L., and Andrus, F. C. (1943). Ibid., 3, 168. Gardner, D. L. (1962). Ibid., 21, 298.

Gedda, P. O. (1955). Acta med. scand., 150, 443.

Gilman, A. (1964). Amer. J. Med., 36, 167.

Grimlund, K. (1963). Acta med. scand., 174, Suppl. 405.

Hench, P. S., Bauer, W., Dawson, M. H., Hall, F., Holbrook, W. P., Key, J. A., and McEwen, C. (1940). Ann. intern. Med., 13, 1837.

Jacobs, L., and Morris, J. G. (1962). Med. J. Aust., 11, 531.

Johnson, R. L., Smyth, C. J., Holt, G. W., Lubchenco, A., and Valentine, E. (1959). Arthr. and Rheum., 2, 224.

Kemper, J. W., Baggenstoss, A. H., and Slocumb, C. H. (1957). Ann. intern. Med., 46, 831.

Kling, D. H. (1952). Ann. rheum. Dis., 11, 299.

Kuhns, J. G., and Joplin, R. J. (1936). New Engl. J. Med., 215, 268.

Larsen, K., and Møller, C. E. (1959). Acta med. scand., 164, 53.

Levin, M. H., Rivo, J. B., Scott, W., Figueroa, W. G., Fred, L., and Barrett, T. F. (1953). Amer. J. Med., 14, 265.

Lindeneg, O., Fischer, S., Pedersen, J., and Nissen, N. I. (1959). Ugeskr. Laeg., 121, 532.

Lipsett, M. B., and Goldman, R. (1954). Ann. Med., 41, 1075.

Moeschlin, S. (1957). Schweiz. med. Wschr., 87, 123.

Nordenfelt, O. and Ringertz, N. (1961). Acta med. scand., 170, 385.
Paulsen, F. (1950). Acta endocr. (Kbh.), 5, 292.

Pollak, V. E., Pirani, C. L., Steck, I. E., and Kark, R. M. (1962). Arthr. and Rheum., 5, 1.

Prescott, L. F. (1965). Lancet, 2, 91.

Randerath, E. (1958). In "Phenacetinabusus und Nierenschädigung," ed. H. Sarre, A. Moench, and R. Kluthe, p. 20 . Thieme, Stuttgart.

Ross, P. (1962). Med. J. Aust., 2, 539.

Sanerkin, N. G., and Weaver, C. M. (1964). Brit. med. J., 1, 288.

Schmid, F. R., Cooper, N. S., Ziff, M., and McEwan, C. (1961). Amer. J. Med., 30, 56.

Schourup, K. (1957). Acta path. microbiol. scand., 41, 462.

Schreiner, G. E. (1962). Ann. intern. Med., 57, 1047.

Snorrason, E. (1950). "Polyarthritis chronica primaria." Thesis. Richter, Copenhagen.

Sørensen, A. W. S. (1963). Acta rheum. scand., 9, 122.

Spühler, O., and Zollinger, H. U. (1953). Z. klin. Med., 151, 1.

Sundelin, F. (1941). Acta med. scand., Suppl. 117.

Teilum, G., and Lindahl, A. (1954). Ibid., 149, 449.

Uehlinger, E. (1958). In "Phenacetinabusus und Nierenschädigung”, p. 1. Thieme, Stuttgart.

West, H. F., and Newns, G. R. (1953). Lancet, 2, 1123.

Wilson, D. (1953). Ibid., 2, 1231.

Zinn, W. (1954). Schweiz. med. Wschr., 84, 125.

La maladie rénale et la médication dans l'arthrite rhumatismale

On examina les dossiers cliniques et de laboratoire de 61 cas d'arthrite rhumatismale (17 hommes et 44 femmes) et on passa en revue leur histologie rénale pour rechercher la fréquence de la maladie rénale.

La maladie rénale à un degré significatif fut trouvée en $72 \%$ des malades et la nécrose papillaire rénale en $21 \%$ d'entre eux; $34 \%$ des malades mourirent en état d'insuffisance rénale.

Le traitement médicamenteux semblait exercer une influence sur la fréquence de la maladie rénale. L'incidence de différentes formes de pyélonéphrite nonocclusive fut significativement plus grande chez des malades recevant de la phénacétine. L'amyloïdose rénale fut plus commune et la nécrose papillaire rénale moins commune chez des malades traités par des corticostéroïdes. On discute la portée de ces observations.

\section{La enfermedad renal y la medicación en la artritis} reumatoide

Se examinaron las fichas clínicas y de laboratorio de 61 casos de artritis reumatoide ( 17 hombres y 44 mujeres) y se revistó la histología renal para estudiar la frecuencia de la enfermedad renal.

La enfermedad renal significativa fué encontrada en un 72 por ciento de los enfermos y la necrosis papilar renal en un 21 por ciento de ellos; un 34 por ciento de enfermos murieron de insuficiencia renal.

El tratamiento medicamentoso pareció ejercer influencia sobre la frecuencia de la enfermedad renal. La incidencia de varias formas de pielonefritis sin obstrucción fué significativamente mayor en enfermos recibiendo fenacetina. La amiloidosis renal fué más común y la necrosis papilar renal lo fué menos en enfermos tratados con corticosteroides.

Se discute la importancia de estas observaciones. 